\title{
Vibration assessment of railway viaducts under real traffic using bridge-track models.
}

\author{
Constança Rigueiro ${ }^{1}$, Carlos Rebelo ${ }^{2 *}$, Luís Simões da Silva ${ }^{2}$ \\ ${ }^{1}$ Department of Civil Engineering, Institute Polytechnic of Castelo Branco, Portugal \\ ${ }^{2}$ Department of Civil Engineering, University of Coimbra, Portugal
}

Email: crebelo@dec.uc.pt; mcsr@est.ipcb.pt

\begin{abstract}
The main purpose of this work is to evaluate and compare the dynamic response of a ballasted single-span simply supported viaduct using available models for the track system composed by the rails, the sleepers and the ballast. The dynamic response obtained from field measurements is used to establish the dynamic characteristics of the structure and the real traffic response acceleration to be used as reference for the comparisons. For the numeric calculations two types of loading model are considered, namely the moving forces model and the interaction bridge/track/vehicle model.
\end{abstract}

Key words: Railways Viaducts, High Speed Train, Ballasted tracks, dynamic models

\section{INTRODUCTION}

Among the several safety checks that must be performed during the design of small to medium single span railway viaducts, the one concerning vertical accelerations is often crucial for high speed railways, since under these conditions resonance is much likely to occur.

Recent results $[4,5,6]$ of several field measurements carried out on simply supported medium span concrete railway viaducts showed that the non-linear behavior of the superstructure composed by ballast and rails can play an important role in the dynamic behavior of the structure and consequent evaluation of its maximum vertical accelerations. The conclusions drawn from those measurements pointed out that the superstructure must be taken into account in the numerical analysis of small to medium span bridges, mainly with respect to the global ballast-structure damping. This revealed to be particularly important when decisions are to be taken, related to the strengthening of existing structures in order to increase traffic speeds and when comfort of passengers is an important issue.

In order to evaluate the vertical vibrations of the bridges when the dynamic behavior of the track is taken into account, the authors $[7,8,9,10,11]$ have already proposed different models including vertical springs, dampers and masses, which are interposed between the loads and the structure in order to simulate the railway track behavior. The main purpose of this paper is to compare the dynamic behavior of ballasted simple supported viaducts with and without the referred track models, taking into account the structural dynamic response obtained from the field measurements, in order to evaluate the influence of the track in the safety check. 


\section{DYNAMIC MODELS OF RAILWAY BALLASTED TRACK}

The railway ballasted track model is made of several elements which represent the rails, the sleepers, the connections between rails and sleepers, and the ballast. The rails are an important component in the track structure, since they transfer the wheel loads and distribute them over the sleepers and supports, guide the wheels in the lateral direction, provide a smooth running surface and distribute acceleration and braking forces over the supports. In Europe the typical rail used in the high speeds lines is the flat-bottom rail, UIC60.

The connections rail/sleeper are materialized by fastenings and rail pads. This system provides the transfer of the rail forces to the sleepers, damps the vibrations and impacts caused by the moving traffic and retains the track gauge and rail inclination within certain tolerances.

The sleepers are elements positioned just below the rails usually made of timber or concrete. They provide support for the rail, sustain rail forces and transfer them as uniformly as possible to the ballast. They preserve track gauge and rail inclination and provide adequate electrical insulation between both rails. The sleepers must be resistant against mechanical and weathering influences over a long period.

Finally, the ballast bed consists of a layer of a coarse-sized, non cohesive, granular material. Traditionally angular, crushed, hard stones and rocks have been considered good ballast materials. The interlocking of ballast grains and their confined condition inside the ballast bed permit the load distributing function and is damping. They also provide the lateral and longitudinal support of the track, as well as the draining effect. The thickness of the ballast bed should allow the sub grade to be loaded as uniformly as possible. The usual depth for the ballast is about 0.3 meters measured from the underside of the sleeper.

In the early studies, the models of the ballasted track were developed in order to investigate the train/track interaction problem. A review of these studies is presented in Fryba [1]. In the 1900's Timoshenko published papers on the strength of rails; later on, Inglis was active in this issue. Knothe [2] and Popp [3] presented an overview of existing tracks models in the field of train/track interaction. The main purpose of these studies in the time domain was to evaluate the deflections of the track and the vertical displacements of the vehicles, while the contact force wheel/rail is evaluated in the calculations. Complete models of the vehicles and the effects of the wheel and rail irregularities are also investigated.

A large variety of ballasted track models has been investigated, from simple 2D model, where a single rail is modeled as an infinite Bernoulli-Euler or Timoshenko beam resting on supports defined by springs, dampers and point masses, to more complex 3D models, where both rails are taken into account and bending and shear deformation of the sleepers are included. In these models, the ballast bed is included through vertical spring and damper elements. Some of these models consider the mass of the ballast as a point mass located below each sleeper and its value is taken relative to the amount of stiffness and damping. Furthermore, shear springs and dampers may interconnect these masses [8].

The values for the mechanical properties of the track components, such as mass, inertia and elasticity, are mentioned as an essential input for dynamic track behavior and, of course, for the study of the interaction between train and track.

Since the purpose of the investigation was on the influence of the ballast track on the vertical vibrations of the railway bridges by comparison of the numerical results with the dynamic response obtained from field measurements, only the 2D tracks models were consider, neglecting unimportant torsion effects.

For this purpose, three different models of ballasted tracks are presented in Figures 1, 2 and 3 [9,10, 11]. In Model I the rails are considered as infinite long beams with in-plane and out-of-plane flexural stiffness as well as axial stiffness. The linear springs and dampers on the vertical and longitudinal directions represent the ballast. These three models are included in the finite element model of the bridge, which is acted by moving loads representing real trains. The model parameters remain constant along the track, despite some deviations due to construction and maintenance works. In the other two models, Model II and Model III, the connections between rail and sleeper are included as linear springs and viscous dampers acting in parallel. Their elastic and damping properties are mainly determined by the properties of the material and the manufacturing processes. The sleepers are included as rigid bodies with point mass. The ballast bed is 
included as discrete linear springs and viscous dampers. In Model III the mass of the ballast is included as point mass instead of distributed mass, and springs and dampers are used to simulate the connection between bridge and ballast [11]. The parameters used in Model II were obtained from [9].

The values of the mechanical properties for each model are included in Table 1 to Table 3.

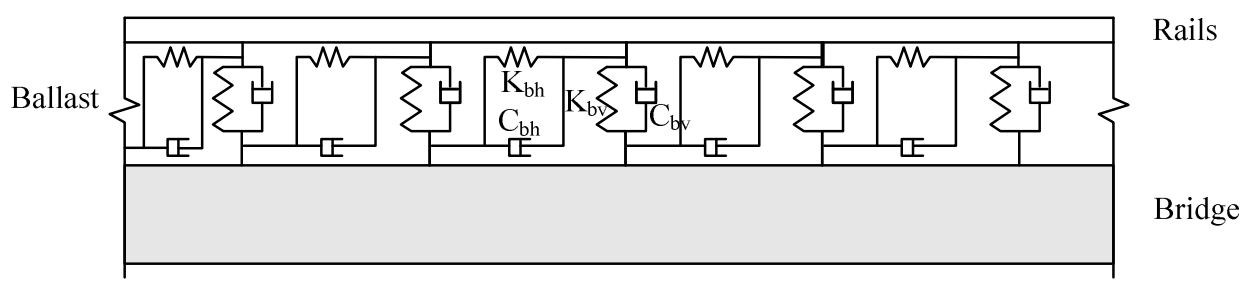

Figure 1: Ballasted track Model I [10].

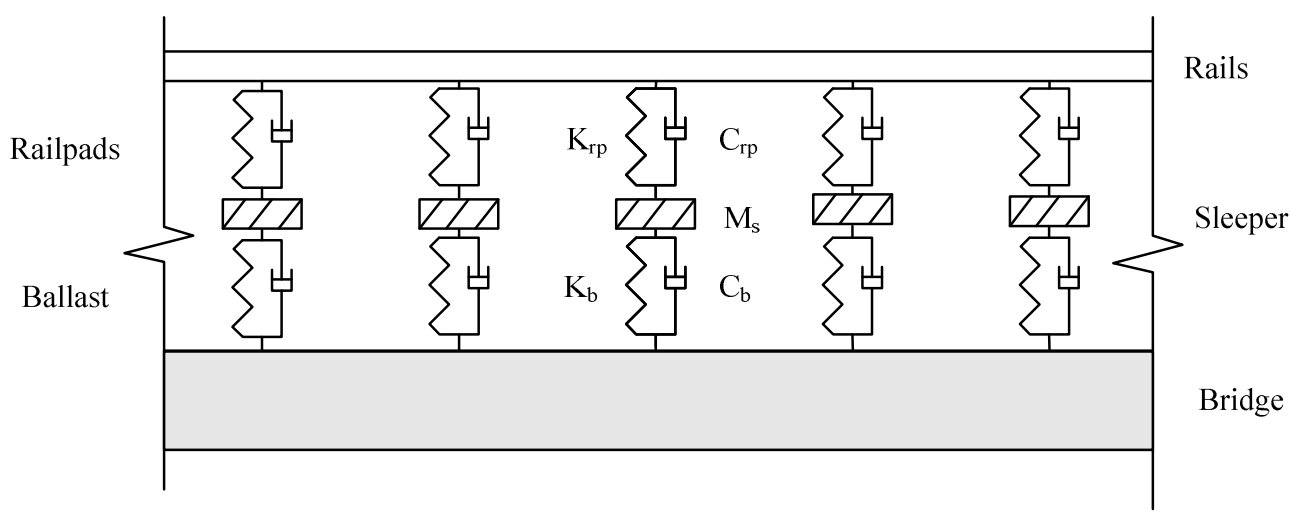

Figure 2: Ballasted track Model II [9].

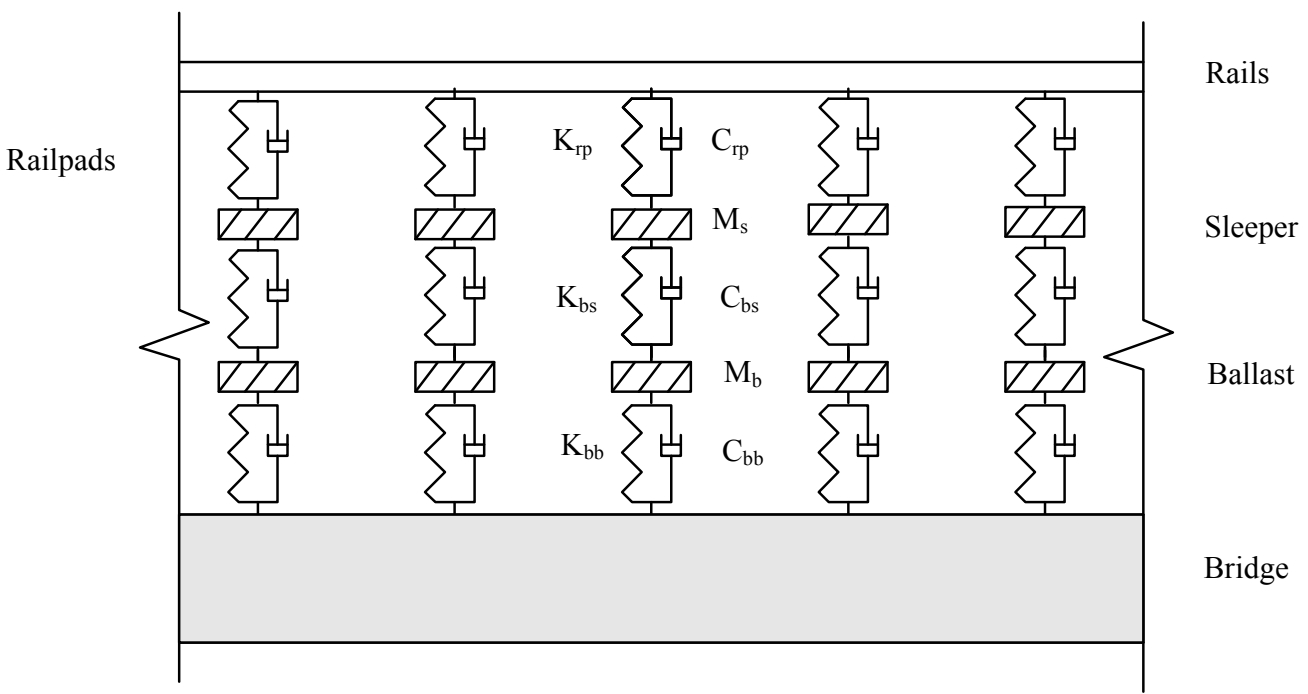

Figure 3: Ballasted track Model III [11].

\begin{tabular}{|c|c|c|c|}
\hline Components of the track model I & Notation & Value & Units \\
\hline \multicolumn{4}{|c|}{$\begin{array}{ll} & \text { Rail UIC60 } \\
\end{array}$} \\
\hline Young Modulus & $\mathrm{E}_{\mathrm{r}}$ & $210 \mathrm{E}+09$ & $\mathrm{~N} / \mathrm{m}^{2}$ \\
\hline Density & $\rho_{\mathrm{r}}$ & 7850 & $\mathrm{~kg} / \mathrm{m}^{3}$ \\
\hline Flexural moment of inertia & $\mathrm{I}_{\mathrm{r}}$ & $3055 \mathrm{E}-08$ & $\mathrm{~m}^{4}$ \\
\hline Sectional area & $A_{r}$ & $76.9 \mathrm{E}-04$ & $\mathrm{~m}^{2}$ \\
\hline
\end{tabular}




\begin{tabular}{|l|c|c|c|}
\hline \hline Per unit of length Vertical stiffness & $\mathrm{K}_{\mathrm{bv}}$ & $104 \mathrm{E}+06$ & $\mathrm{~N} / \mathrm{m}$ \\
\hline Per unit of length Vertical damping & $\mathrm{C}_{\mathrm{bv}}$ & $50 \mathrm{E}+03$ & $\mathrm{~N} . \mathrm{s} / \mathrm{m}$ \\
\hline Per unit of length Horizontal stiffness & $\mathrm{K}_{\mathrm{bh}}$ & $104 \mathrm{E}+06$ & $\mathrm{~N} / \mathrm{m}$ \\
\hline Per unit of length Horizontal damping & $\mathrm{C}_{\mathrm{bh}}$ & $50 \mathrm{E}+03$ & $\mathrm{~N} . \mathrm{s} / \mathrm{m}$ \\
\hline \hline
\end{tabular}

Table 1: Properties of track Model I [10].

\begin{tabular}{|l|c|c|c|}
\hline \multicolumn{1}{|c|}{ Components of the track model II } & Notation & Value & Units \\
\hline \hline \multicolumn{2}{|c|}{ Rail UIC60 } \\
\hline \hline Young Modulus & $\mathrm{E}_{\mathrm{r}}$ & $210 \mathrm{E}+09$ & $\mathrm{~N} / \mathrm{m}^{2}$ \\
\hline Density & $\rho_{\mathrm{r}}$ & 7850 & $\mathrm{~kg} / \mathrm{m}^{3}$ \\
\hline Flexural moment of inertia & $\mathrm{I}_{\mathrm{r}}$ & $3055 \mathrm{E}-08$ & $\mathrm{~m}^{4}$ \\
\hline Sectional area & $\mathrm{A}_{\mathrm{r}}$ & $76.9 \mathrm{E}-04$ & $\mathrm{~m}^{2}$ \\
\hline \hline \multicolumn{4}{|c|}{ Connection rail/sleeper } \\
\hline Vertical stiffness & $\mathrm{K}_{\mathrm{rp}}$ & $300 \mathrm{E}+06$ & $\mathrm{~N} / \mathrm{m}$ \\
\hline Vertical damping & $\mathrm{C}_{\mathrm{rp}}$ & $80 \mathrm{E}+03$ & $\mathrm{~N} . \mathrm{s} / \mathrm{m}$ \\
\hline \hline \multicolumn{4}{|c|}{ Sleeper } \\
\hline \hline Mass & $\mathrm{M}_{\mathrm{s}}$ & 300 & $\mathrm{~kg}$ \\
\hline Length between sleepers & $\mathrm{d}_{\mathrm{s}}$ & 0.60 & $\mathrm{~m}$ \\
\hline \hline \multicolumn{4}{|c|}{ Ballast } \\
\hline \hline Vertical stiffness & $\mathrm{K}_{\mathrm{b}}$ & $120 \mathrm{E}+06$ & $\mathrm{~N} / \mathrm{m}$ \\
\hline Vertical damping & $\mathrm{C}_{\mathrm{b}}$ & $114 \mathrm{E}+03$ & $\mathrm{~N} . \mathrm{s} / \mathrm{m}$ \\
\hline
\end{tabular}

Table 2: Properties of track Model II [9].

\begin{tabular}{|c|c|c|c|}
\hline Components of the track model III & Notation & Value & Units \\
\hline \multicolumn{4}{|c|}{ Rail UIC60 } \\
\hline Young Modulus & $\mathrm{E}_{\mathrm{r}}$ & $210 \mathrm{E}+09$ & $\mathrm{~N} / \mathrm{m}^{2}$ \\
\hline Density & $\rho_{\mathrm{r}}$ & 7850 & $\mathrm{~kg} / \mathrm{m}^{3}$ \\
\hline Flexural moment of inertia & $\mathrm{I}_{\mathrm{r}}$ & $3055 \mathrm{E}-08$ & $\mathrm{~m}^{4}$ \\
\hline Sectional area & $\mathrm{A}_{\mathrm{r}}$ & 76.9E-04 & $\mathrm{m}^{2}$ \\
\hline \multicolumn{4}{|c|}{ Connection rail/sleeper } \\
\hline Vertical stiffness & $\mathrm{K}_{\mathrm{rp}}$ & $500 \mathrm{E}+06$ & $\mathrm{~N} / \mathrm{m}$ \\
\hline Vertical damping & $\mathrm{C}_{\mathrm{rp}}$ & $200 \mathrm{E}+03$ & N.s/m \\
\hline \multicolumn{4}{|c|}{ Sleeper } \\
\hline Mass & $\mathrm{M}_{\mathrm{s}}$ & 290 & $\mathrm{~kg}$ \\
\hline Length between sleepers & $\mathrm{d}_{\mathrm{s}}$ & 0.60 & $\mathrm{~m}$ \\
\hline \multicolumn{4}{|c|}{ Ballast } \\
\hline Vertical stiffness ballast/sleeper & $\mathrm{K}_{\mathrm{bs}}$ & $538 \mathrm{E}+06$ & $\mathrm{~N} / \mathrm{m}$ \\
\hline Vertical damping ballast/sleeper & $\mathrm{C}_{\mathrm{bs}}$ & $120 \mathrm{E}+03$ & N.s/m \\
\hline Mass & $\mathrm{M}_{\mathrm{b}}$ & 412 & $\mathrm{~kg}$ \\
\hline Vertical stiffness bridge/ballast & $\mathrm{K}_{\mathrm{bb}}$ & $1000 \mathrm{E}+06$ & $\mathrm{~N} / \mathrm{m}$ \\
\hline Vertical damping bridge/ballast & $\mathrm{C}_{\mathrm{bb}}$ & $50 \mathrm{E}+03$ & N.s/m \\
\hline
\end{tabular}

Table 3: Properties of track Model III [11]. 


\section{ANALYSIS OF A RAILWAY BRIDGE}

\subsection{Description of the Bridge}

In this item the dynamic behavior of a medium span railway bridge $[4,6]$ subject to real traffic is analyzed. The bridge deck is a simply supported slab spanning over 23.5 meters, made of prestressed concrete with a slightly variable depth and a mass per unit length of about $21 \mathrm{Ton} / \mathrm{m}$. The geometrical characteristics are shown in Figure 4.

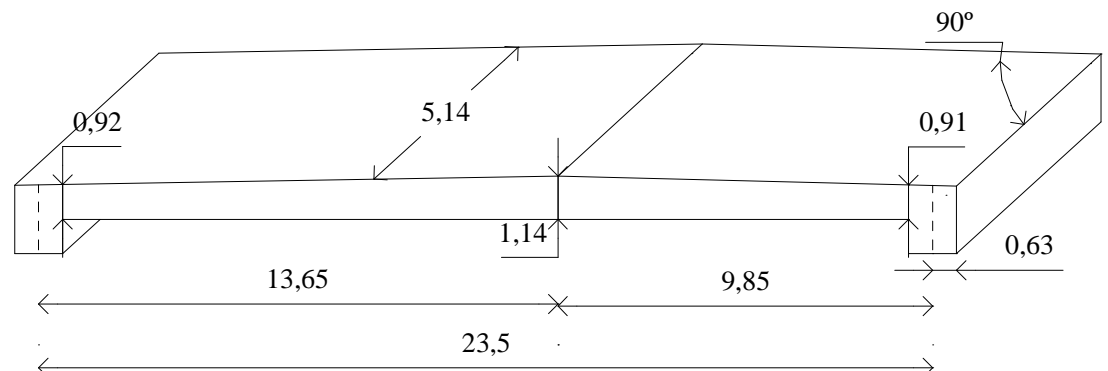

Figure 4: Structural layout of the bridge.

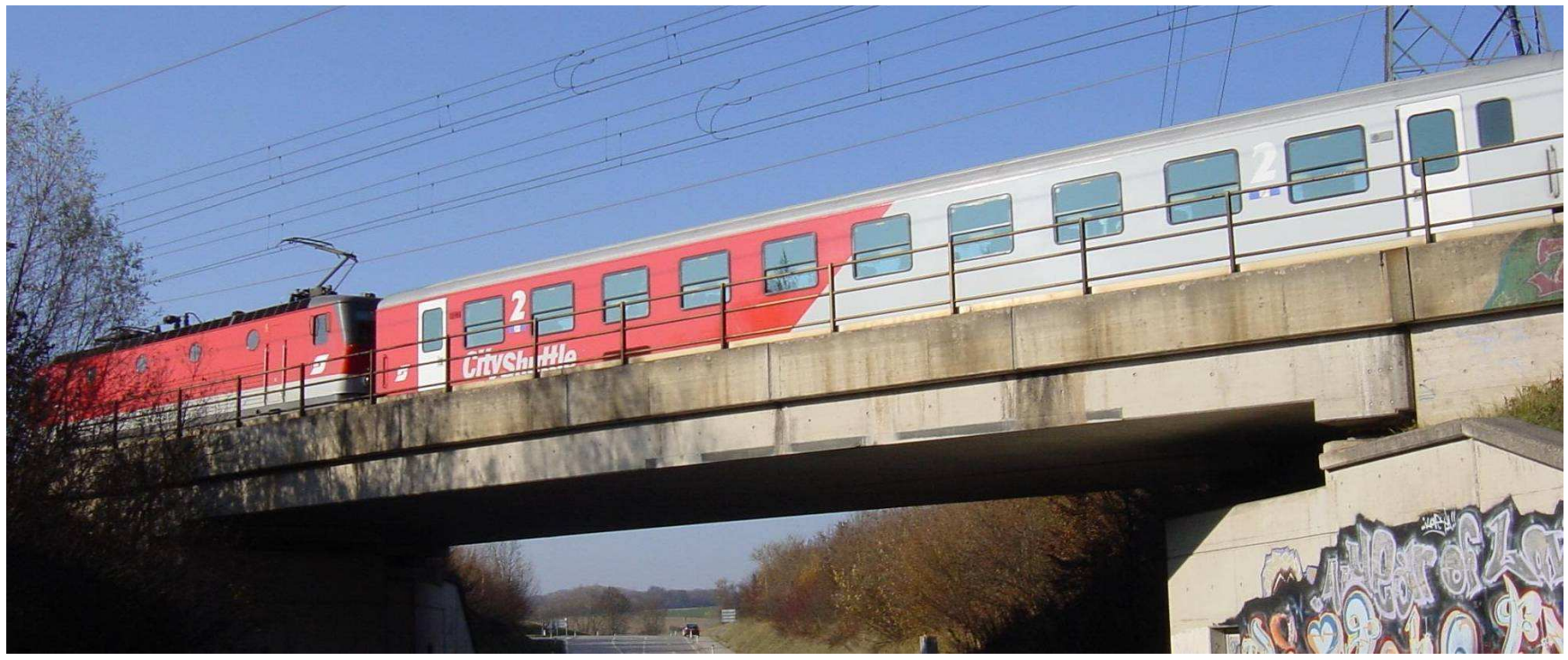

Figure 4a: General view of the bridge.

The bearing supports, two at each extremity of the slab, as shown in Figure 5, are made of steel pots filled with elastomeer. There is no continuity of the slab over the supports to the abutments, except the one materialized by the ballast track, see Figure 6.

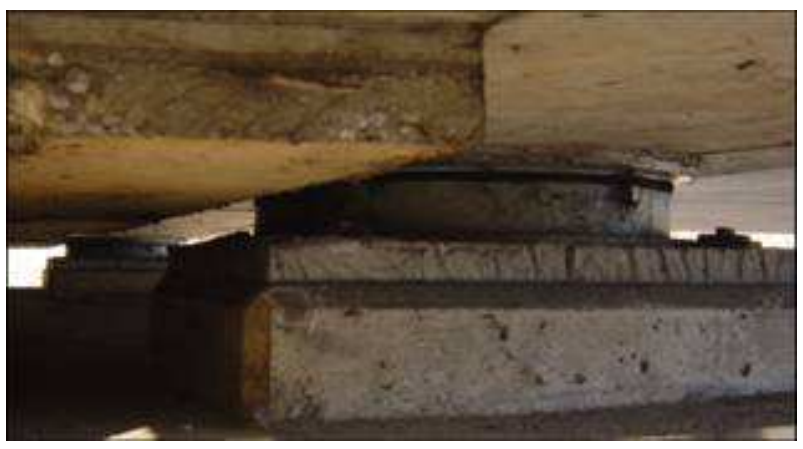

Figure 5: Bearings supports.

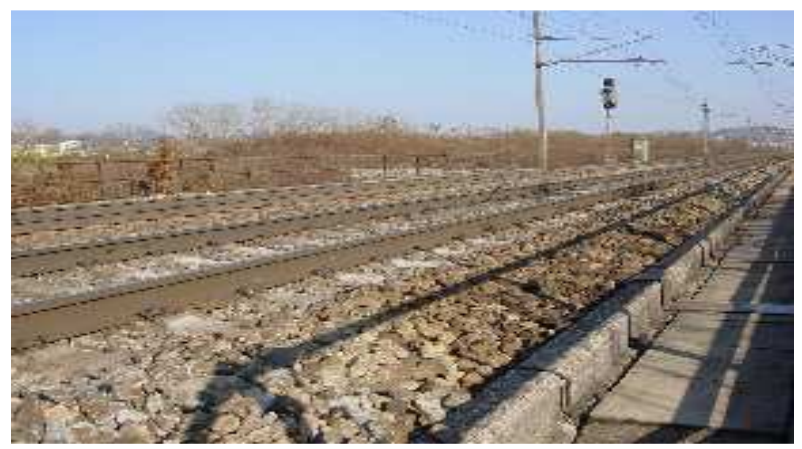

Figure 6: View of the railway track over the bridge. 


\subsection{Numerical Model}

Using the software RM2004 [14] a numerical model was developed with the purpose of comparing the computed dynamic characteristics, modes, frequencies and damping, with those obtained from measurements. Although the structural layout used for the bridge design corresponds to a simply supported bridge, the measurements showed that the bridge behaves as a simply supported slab with some flexural stiffness at the supports. Therefore, the numerical model includes a spring of stiffness $\mathrm{K}_{\text {rail }}$ over the supports at the level of the rails (see Fig. 7) simulating the continuity of the rail track, and a spring of stiffness $K_{s}$ at the level of the bearing supports, simulating the slip resistance.

Since, in this model, only the rail axial stiffness can be estimated from the rail characteristics, and no information can be obtained for the slip resistance of the supports, this stiffness $\mathrm{K}_{\mathrm{s}}$ was considered equal to $\mathrm{K}_{\text {rail }}$, which can be estimated by

$$
\mathrm{K}_{\text {rail }}=\frac{\mathrm{E}_{\mathrm{r}} \times \mathrm{A}_{\mathrm{r}}}{4 \times \mathrm{d}_{\mathrm{s}}}
$$

where $E_{r}, A_{r}$ and $d_{s}$ correspond to the Young modulus, section area and length between sleepers, with values given in Table 1 . Using these values, $\mathrm{K}_{\mathrm{s}}=\mathrm{K}_{\mathrm{rail}}=670 \mathrm{MN} / \mathrm{m}$.

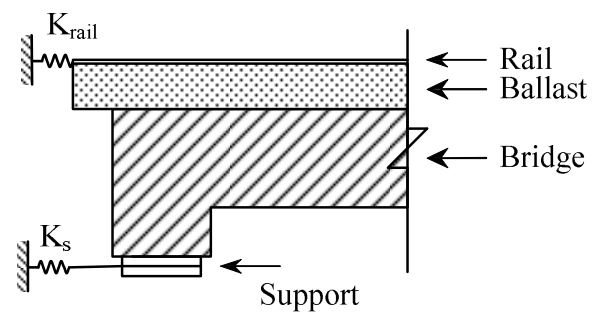

Figure 7: Model of the support.

Other values for the concrete properties used in the computations are: specific weight, $\gamma_{\mathrm{c}}=25 \mathrm{kN} / \mathrm{m}^{2}$, Young modulus $\mathrm{E}_{\mathrm{c}}=54.6 \mathrm{GPa}$. For the ballast, the specific weight $\gamma_{\mathrm{b}}=20 \mathrm{kN} / \mathrm{m}^{2}$ was considered.

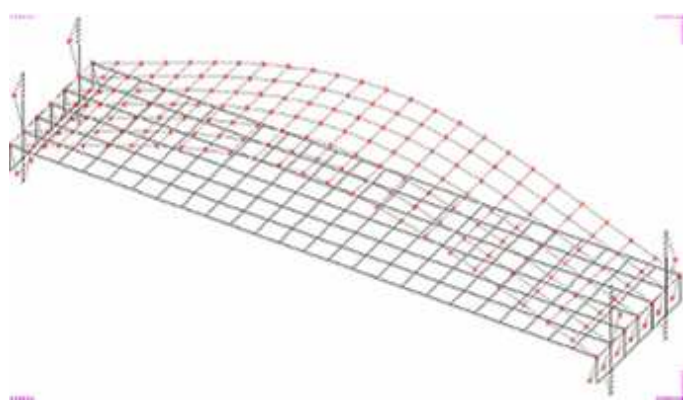

$\mathrm{F}_{1}=4.40 \mathrm{~Hz}$

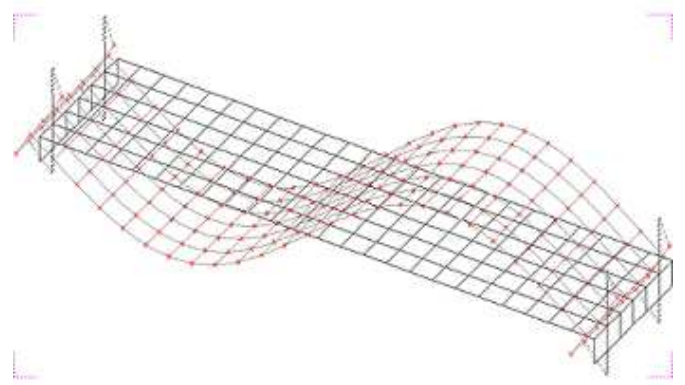

$\mathrm{F}_{2}=13.70 \mathrm{~Hz}$ 

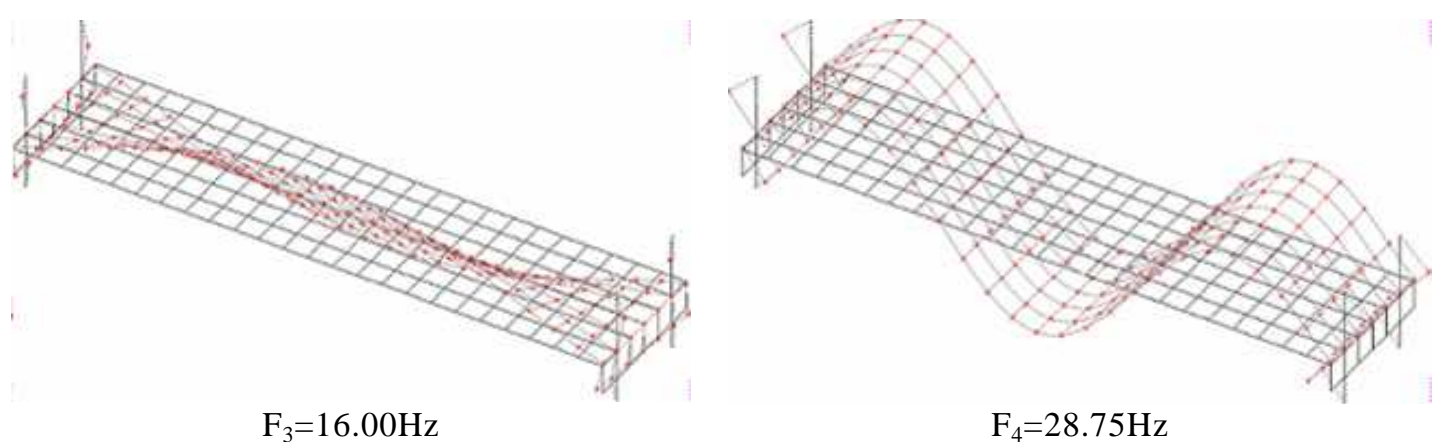

Figure 8: Computed natural modes and frequencies of the bridge.

The values of the natural frequencies of the model are in good agreement with those from free low amplitude vibration measurements. However, if larger amplitudes are considered, as it happens when the bridge is loaded during train passages, the agreement is poorer due to the non-linear behavior of the support flexural stiffness included in the model [5]. To adjust the model to the measured response during forced vibrations, a lower stiffness was considered and the first natural frequency of the bridge decreased about $10 \%$ approximating $4.01 \mathrm{~Hz}$.

\subsection{Dynamic Response during train passages}

In this item the numeric dynamic response is computed and compared with the response obtained from the measurements. The main purpose is to analyze the vibration of the bridge with and without consideration of the track models. The results are obtained separately for the moving forces model and for the model including interaction between train and bridge. Two different trains are considered for the comparison: (i) a single locomotive type 1116 and (ii) an ICE train with seven vehicles - power car type 1044 and six carriages type 2094.

\subsubsection{Some Considerations about the Dynamic Analyses}

The dynamic response is computed by direct time integration of the system of the dynamic equilibrium differential equations using the Newmark and the Wilson- $\theta$ methods. For these unconditionally stable algorithms a time step may be selected independent of stability considerations and thus can result in a substantial saving of computational effort. In addition to being unconditionally stable, when only low mode response is of interest it is often advantageous for an algorithm to have same form of numerical dissipation to damp out any spurious participation of the higher modes. Same examples of algorithm commonly used in structural dynamic which possess these proprieties are the Wilson $\theta$ method and the Newmark family of methods, restricted to parameter values of $\gamma>1 / 2$ and $\beta \geq 0.25 \times(\gamma+1 / 2)^{2}$, where the amount of dissipation, for a fixed time step $\Delta \mathrm{t}$, is increased by increasing $\gamma$. On the other hand, the dissipative properties of this family of algorithms are considered to be worse then the Wilson- $\theta$ method, since the lower modes are strongly affected. The Wilson $\theta$ method, with $\theta=1.4$, is highly dissipative at the highest modes, unconditionally stable and accurate when $\Delta t / T_{n} \leq 0.01$, where $T_{n}$ is the lowest vibration period to take into account in the structural response analysis,[16].

Concerning the damping, the Rayleigh matrix was used, that is, $\mathrm{C}=\alpha \cdot \mathrm{M}+\beta \cdot \mathrm{K}$, with constants $\alpha=2.507$ and $\beta=6.983 \mathrm{E}-04$, which correspond to a damping ratio, for the first frequency of the bridge of about 
$5 \%$. Although this value is higher than the one recommended in [13], it is the value obtained from the vibration measurements in that bridge.

At first, the analysis of the bridge using the moving forces model is performed. In this simple methodology, the interaction effects between train and bridge is neglected. A second analysis, using the more complex methodology that takes into account the referred interaction is performed. In this case two situations are considered: (i) the only-bridge model and (ii) the bridge-track model. All the computations are made using the algorithm of contact between several bodies implemented in software ADINA [12].

The interaction model including the traveling mass-damping-stiffness systems of the train are schematically shown in Figure 9 for the track Model I. The traveling systems represent the primary suspension and the mass of the vehicles. This simplified form consider that the mass of the traveling system is equal to one quarter of the whole vehicle mass and that the stiffness and damping are taken equal to the primary suspension. Unsprung mass of the wheelsets is neglected.

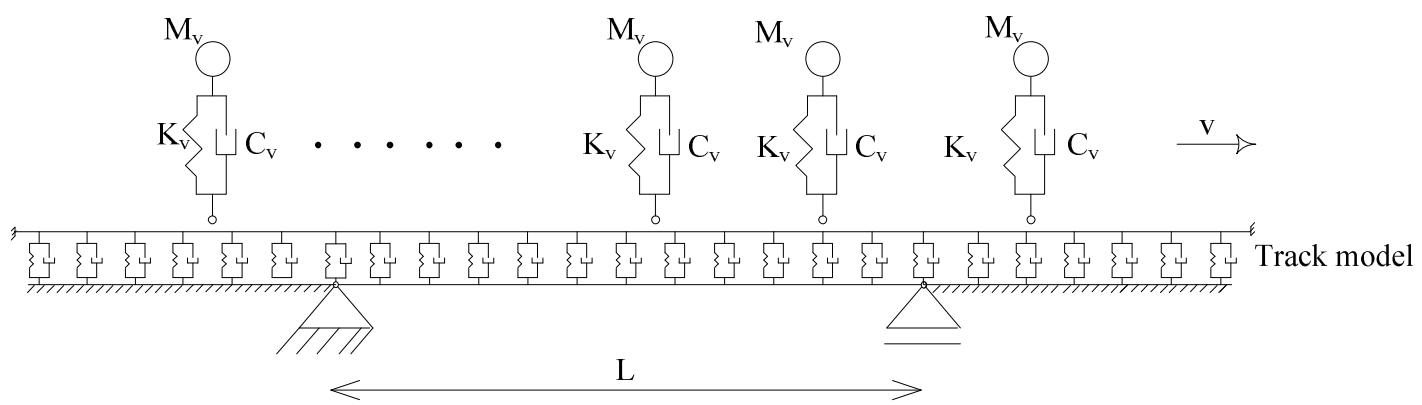

Figure 9: Simplified interaction model.

\subsubsection{Analysis of the Locomotive type 1116 passage}

The locomotive data for the moving forces model is represented in Figure 10. The speed of the locomotive, $130 \mathrm{~km} / \mathrm{h}$, was measured with a speedometer when it passed over the bridge.

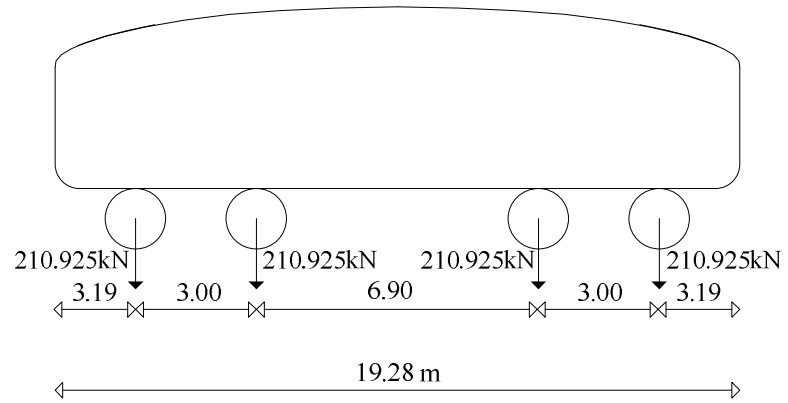

Figure 10: Locomotive type 1116.

${ }^{\mathrm{i}}$ For a prestressed concrete bridge, with span greater then 20 meters, the modal damping to be adopted in the dynamic analysis according to [13] should be $1 \%$. 


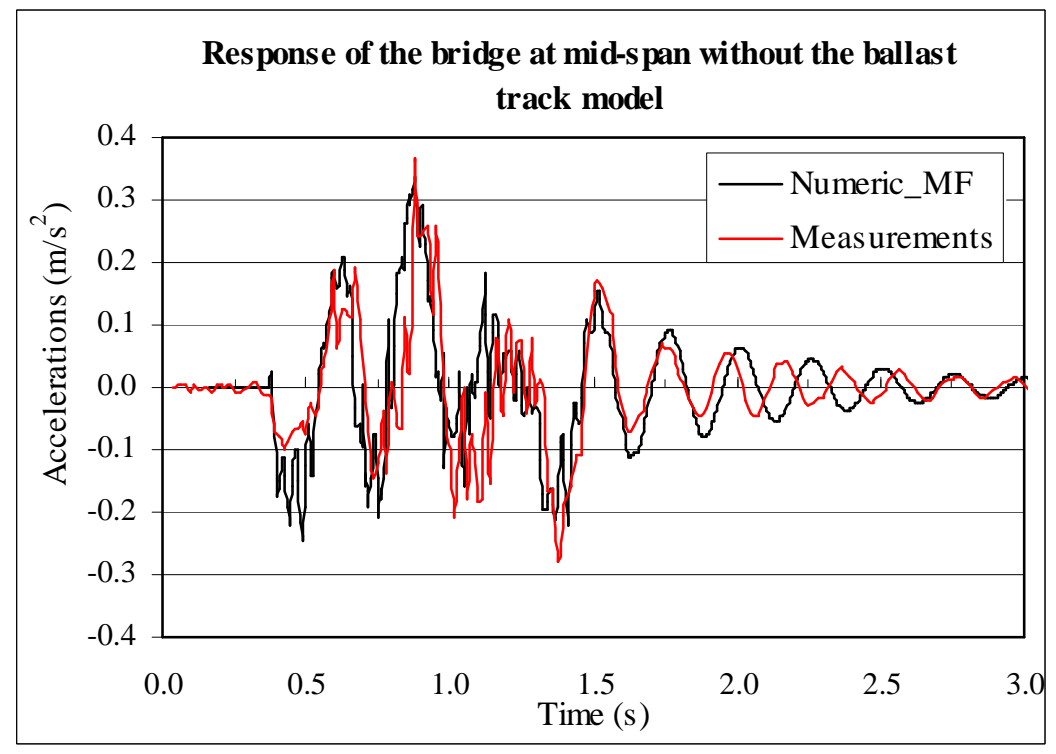

Figure 11: Comparison between numeric and measured response of the bridge, without the track model, during the passage of the locomotive.

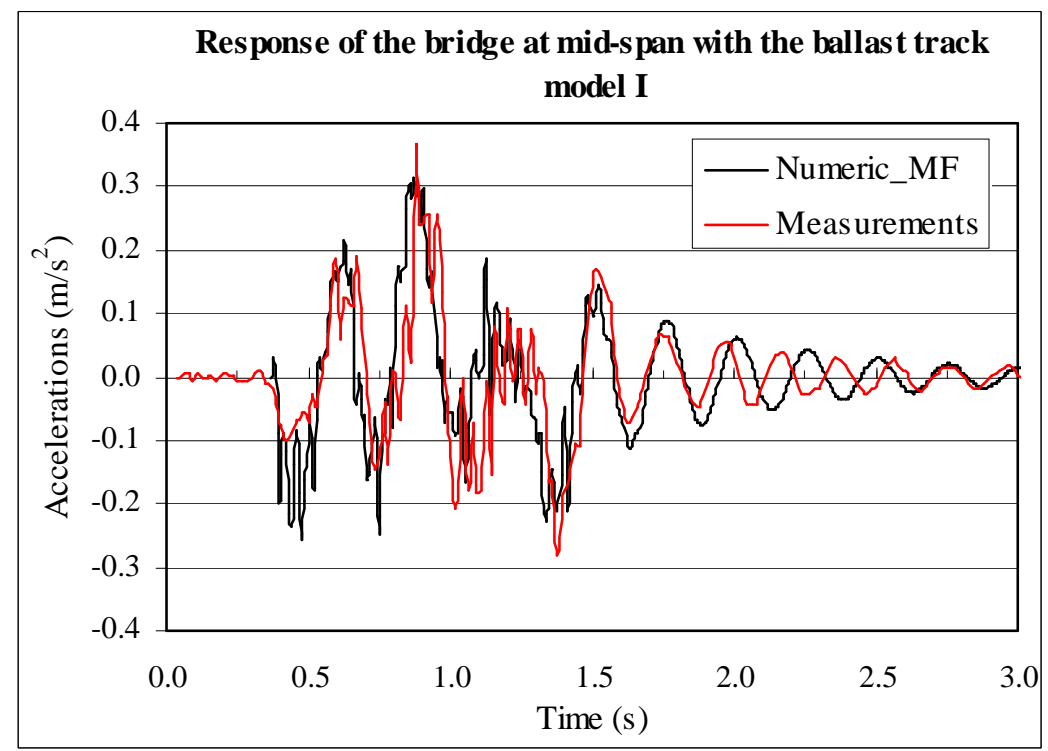

Figure 12: Comparison between numeric and measured response of the bridge, with the track Model I, during the passage of the locomotive..

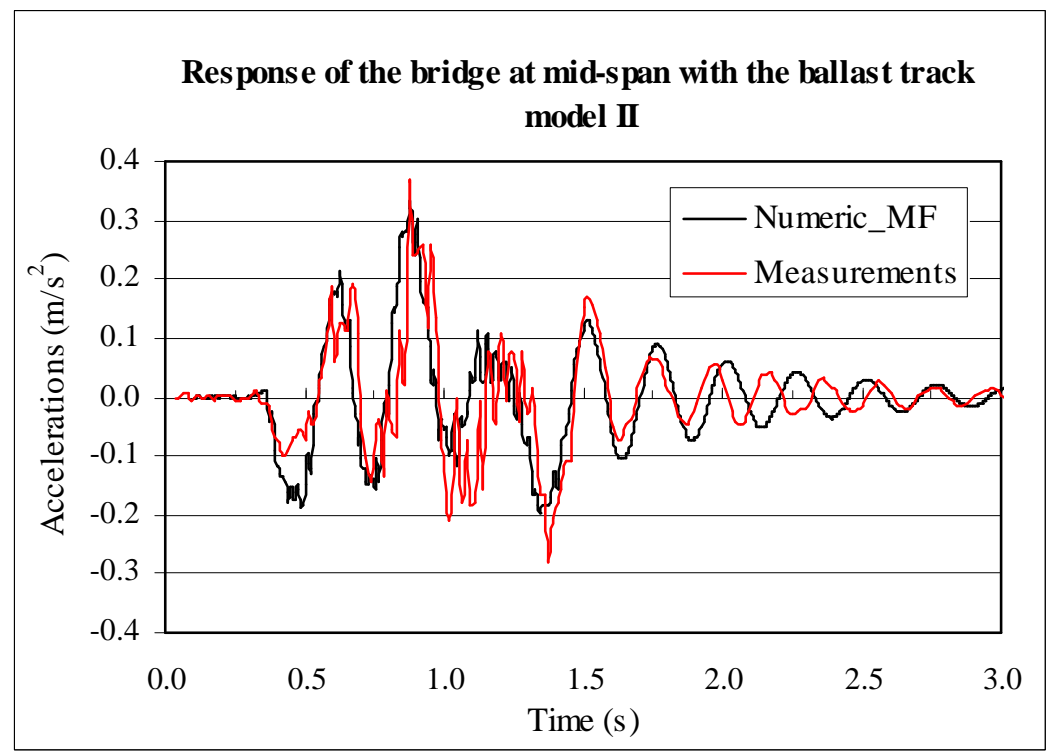

Figure 13: Comparison between numeric and measured response of the bridge, with the track Model II, during the passage of the locomotive.. 


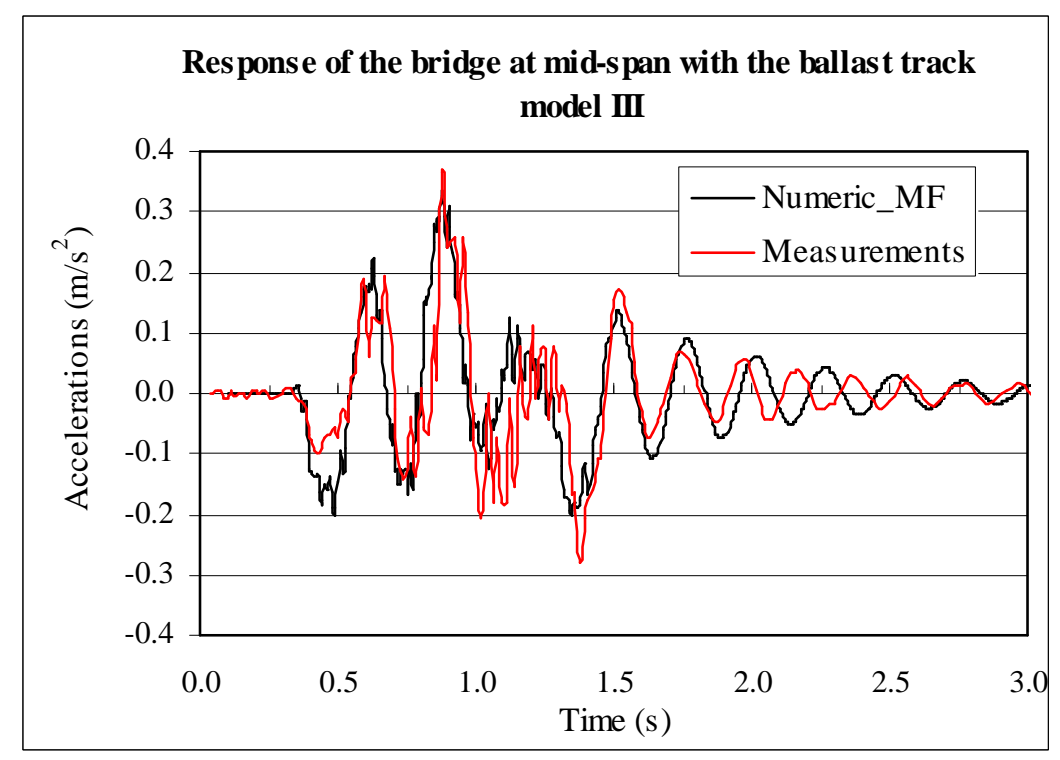

Figure 14: Comparison between numeric and measured response of the bridge, with the track Model III, during the passage of the locomotive..

Figure 11 to Figure 14 depict the comparison between the measured and the computed acceleration at the mid-span of the bridge for all studied cases, without and with the ballast track models, considering the moving load model. Analyzing the evolution of the times histories, it is obvious that during the passage of the locomotive, all the numeric responses fit very well. In the numeric model, the first frequency at $4.01 \mathrm{~Hz}$ remains constant for the entire duration. In the measurements, for the initials seconds when the locomotive is on the bridge, the first frequency match quite well with the $4.01 \mathrm{~Hz}$, after the passage of the vehicle, an increase on the value of the frequency is observed, confirming what was stated before.

In addition to that, the measurements reflect the influence of the vehicle mass in the first frequency of the bridge. If one considers the mass of the vehicle on the bridge, the modified first frequency of the bridge $\mathrm{f}_{\mathrm{b}}^{*}$, can be estimated as follows

$\mathrm{f}_{\mathrm{b}}^{*}=\sqrt{\frac{\overline{\mathrm{m}}_{\mathrm{b}}}{\overline{\mathrm{m}}_{\mathrm{b}}+\mathrm{M}_{\mathrm{v}} / \mathrm{L}}} \cdot \mathrm{f}_{\mathrm{b}}$

where $M_{v}$ represents the total mass of the vehicle. Assuming the mass of the locomotive to be $M_{v}=86000 \mathrm{~kg}$ the first natural frequency of the bridge is likely to decrease to about $\mathrm{f}_{\mathrm{b}}^{*}=3.70 \mathrm{~Hz}$, during the passage of the locomotive. This value remains constant until the locomotive leaves the bridge, what happens at time $1.4 \mathrm{~s}$. After that the first frequency of the bridge increases passing throw the value, referred in Figure 8, up to $5.2 \mathrm{~Hz}$ as identified in the free vibration measurements [6]. In terms of damping, the comparison between the calculations and the measurements, for the bridge in free vibration, fits quite well, so $\xi=0.05$ seems to be suitable.

Analyzing Figure 12 to Figure 14, the values calculated for the bridge considering the track models are similar to those calculated without the track models. However, the use of the ballast track model suppresses the contribution of frequency components of the bridge response in the range $20-30 \mathrm{~Hz}$, acting as a low pass filter. This effect is shown in Figure 15, where the representation is made in the frequency domain. From this point of view the track model III is the most efficient in filtering the higher frequencies. 


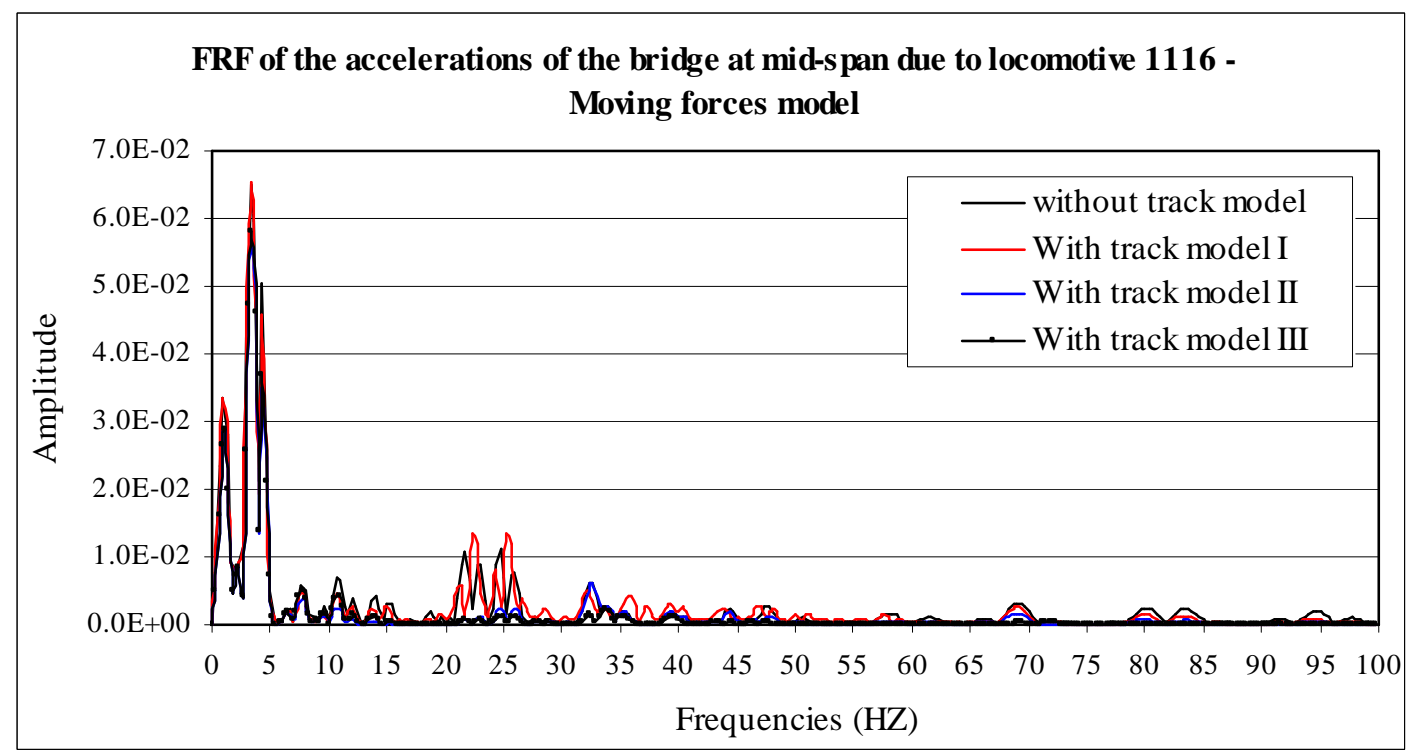

Figure 15: Frequency domain representation of the response acceleration of the bridge mid-span section taking for all the three ballast track models.

Unlike the case of the ICE, the values of the stiffness and damping of the primary suspension of the locomotive are not known, therefore no comparison between the numerical results, using interaction, and the measurements is presented. Nevertheless, a preliminary study using assumed values was done, which showed that those values of the primary suspension decisively influence the results.

\subsubsection{ICE train}

The available measurements include the acceleration response to the passage of the ICE train, at a speed of $140 \mathrm{~km} / \mathrm{h}$, with seven vehicles as defined before and shown in Figure $16^{\mathrm{ii}}$.

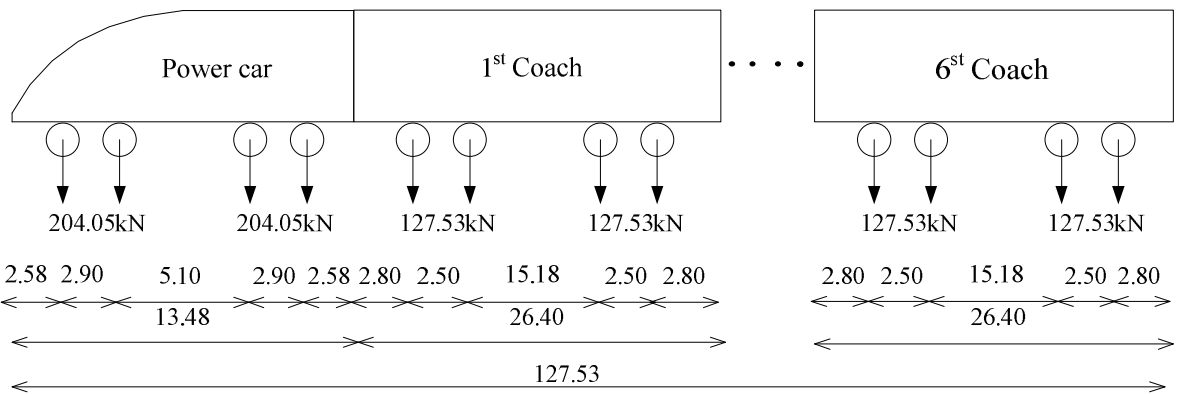

Figure 16: Train ICE549, identical ICE train.

Figure 17 to Figure 20 compare the measured and the computed acceleration at the mid-span of the bridge for all cases, with and without the ballast track models, considering the moving load model. The represented time histories point out the goodness of fit between the numeric response and the measurements. The damping $\xi=0.05$ for the first frequency seems to fit quite well, once again. The decreasing of the first natural frequency only takes place when the power car passes over the bridge, because of its high mass and because the distance between the boogies of the coaches is greater than the span of the bridge.

\footnotetext{
ii The ICE train characteristics defined in [13] are somewhat different from those in the figure, which correspond to the real on.
} 


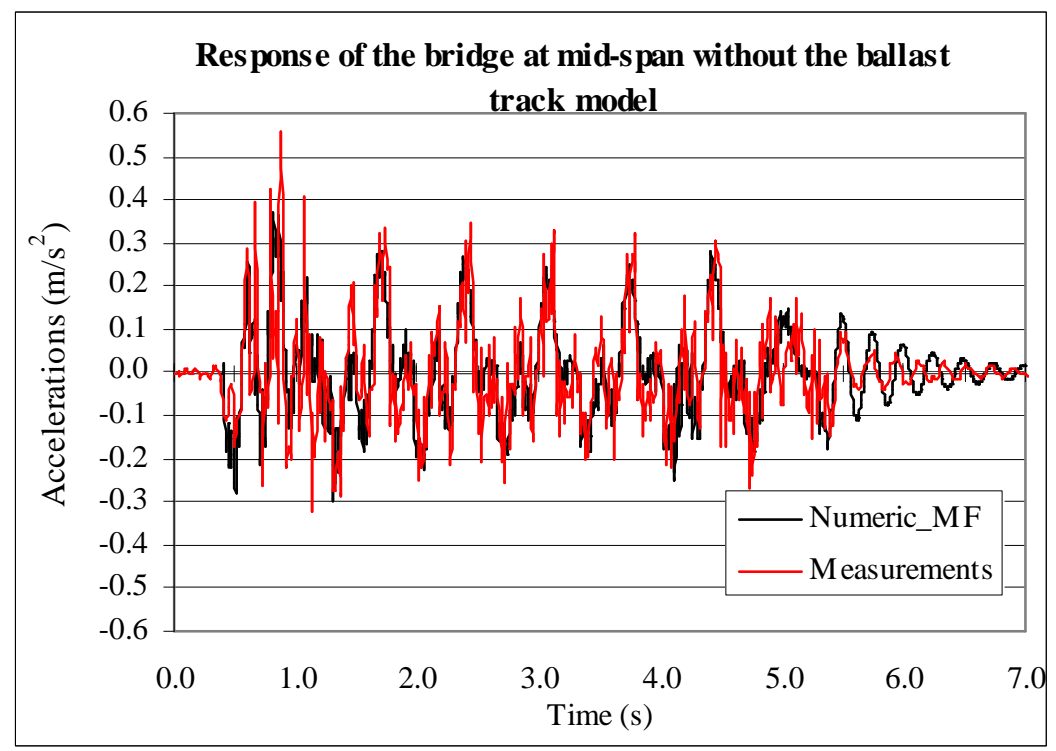

Figure 17: Comparison between numeric and measured response of the bridge, without any track model, subject to the passage of the ICE549 train at a speed of $140 \mathrm{~km} / \mathrm{h}$.

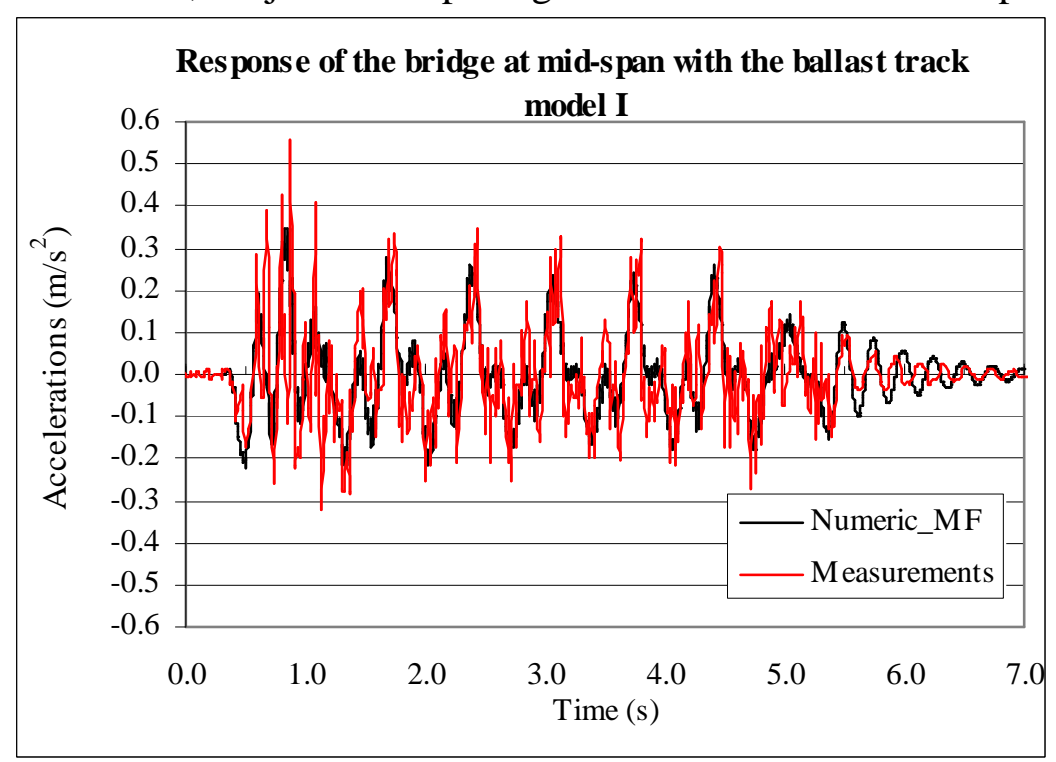

Figure 18: Comparison between numeric and measured response of the bridge, with a track model I, subject to the passage of the ICE549 train at a speed of 140km/h.

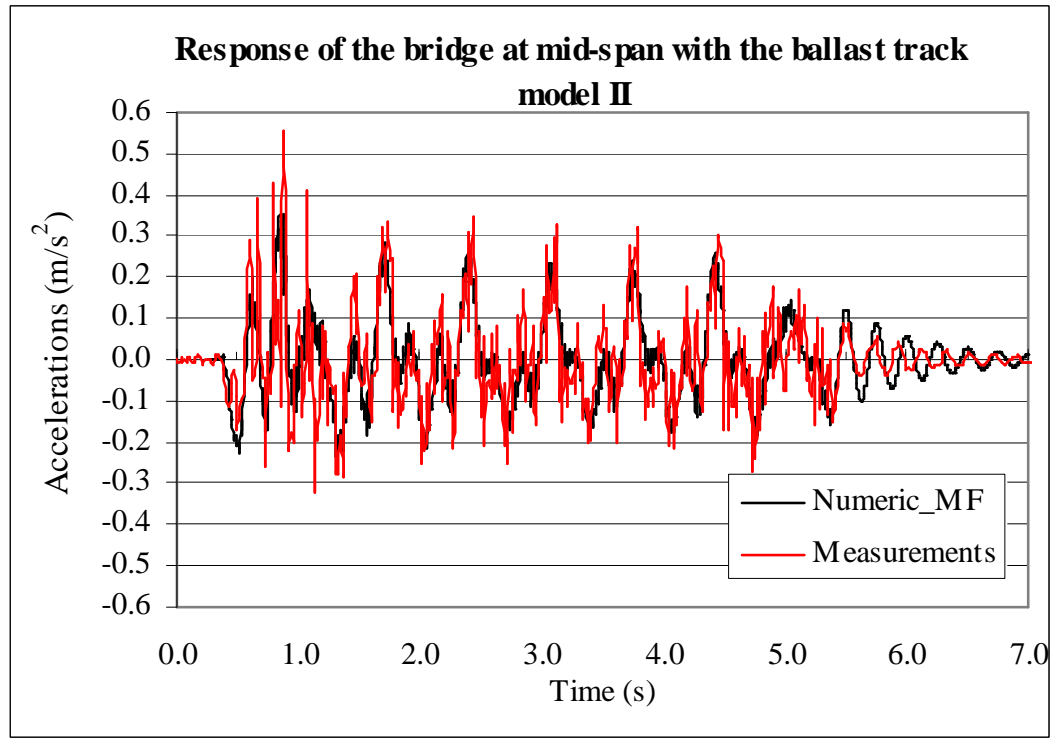

Figure 19: Comparison between numeric and measured response of the bridge, with a track model II, subject to the passage of the ICE549 train at a speed of $140 \mathrm{~km} / \mathrm{h}$. 


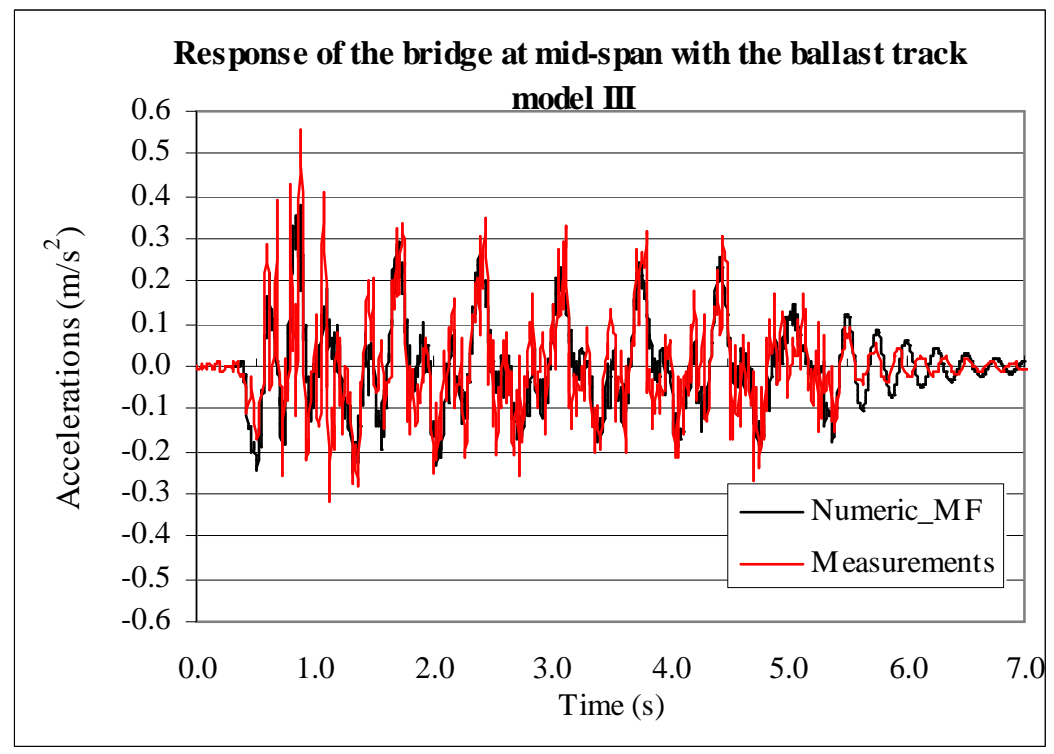

Figure 20: Comparison between numeric and measured response of the bridge, with a track model III, subject to the passage of the ICE549 train at a speed of 140km/h.

The results in time domain obtained from the model of the bridge with and without any track model are similar. However, if the comparison is made in the frequency domain, it is concluded that the ballast track Models I and II influence the response at a frequency range between 15 and $45 \mathrm{~Hz}$ (see Figure 21). The track Model III seems to concentrate its influence around 20-25 Hz (see Figure 22).

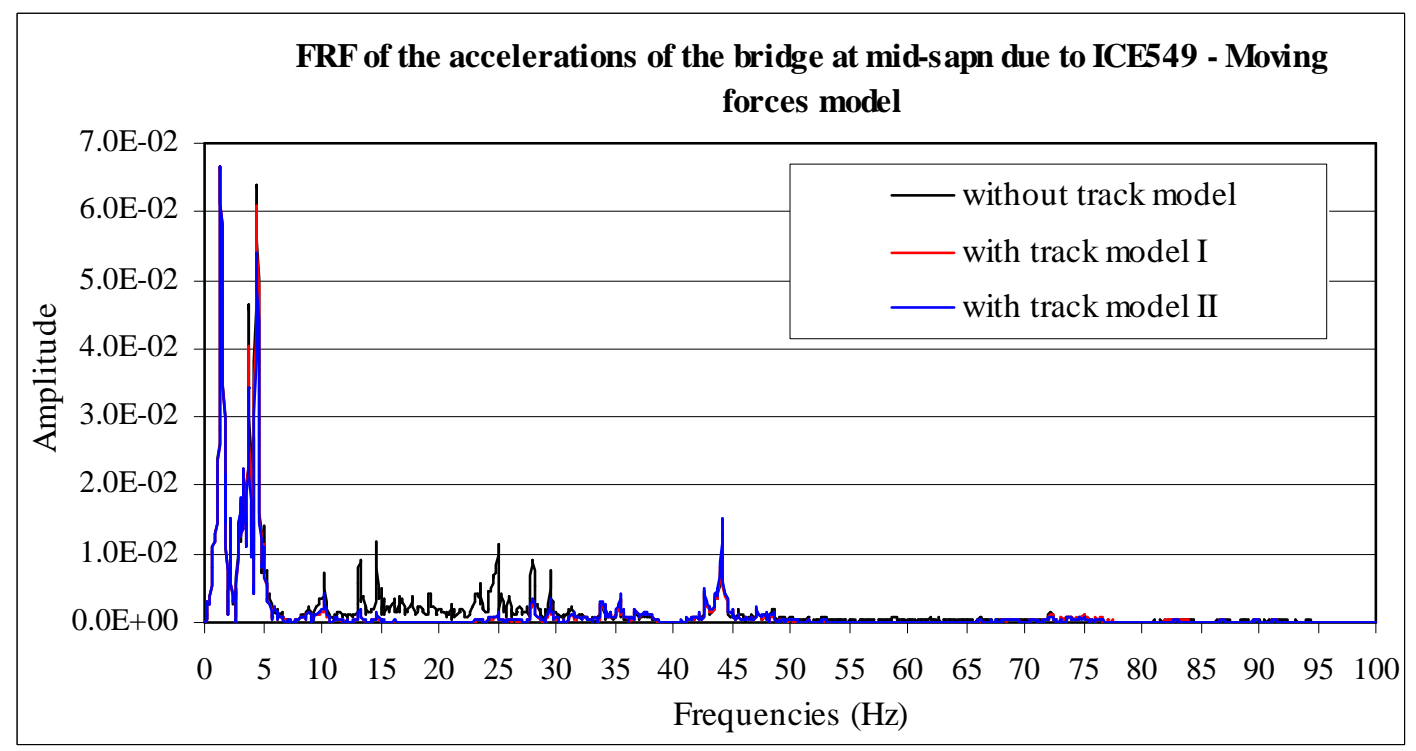

Figure 21: Comparison of the accelerations of the bridge with a track model I and II in frequency domain during the passage of the ICE549 train at a speed of $140 \mathrm{~km} / \mathrm{h}$. 


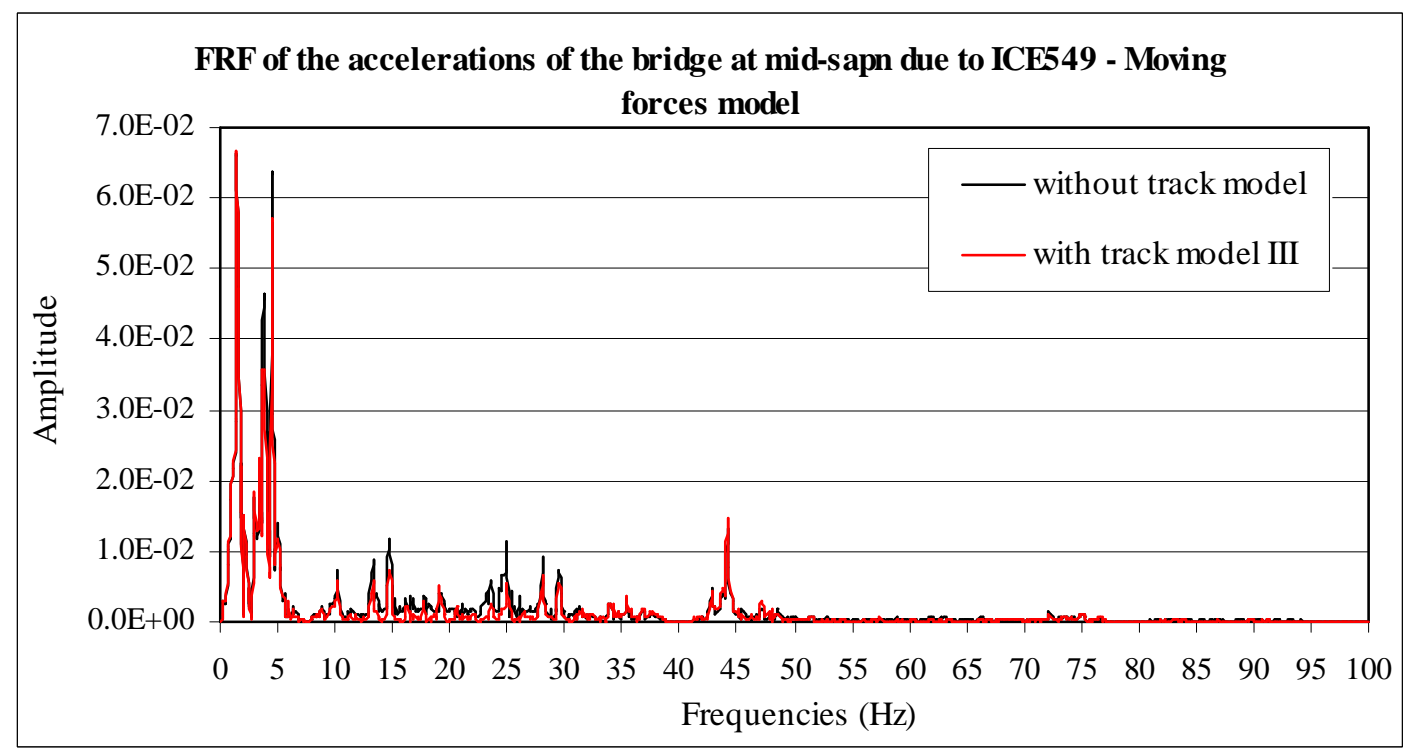

Figure 22: Comparison of the accelerations of the bridge with a track model III in frequency domain during the passage of the ICE549 train at a speed of $140 \mathrm{~km} / \mathrm{h}$.

Analyzing the frequency response accelerations at the mid-span of the bridge taking into account the train-track-bridge interaction model with different systems (see Figure 23), it is concluded once again that the ballast track model acts like a low-pas filter. The results considering train-bridge interaction without any track model show a contribution of higher frequencies when compared with the equivalent system when the moving force model is used (compare figures 22 and 23).

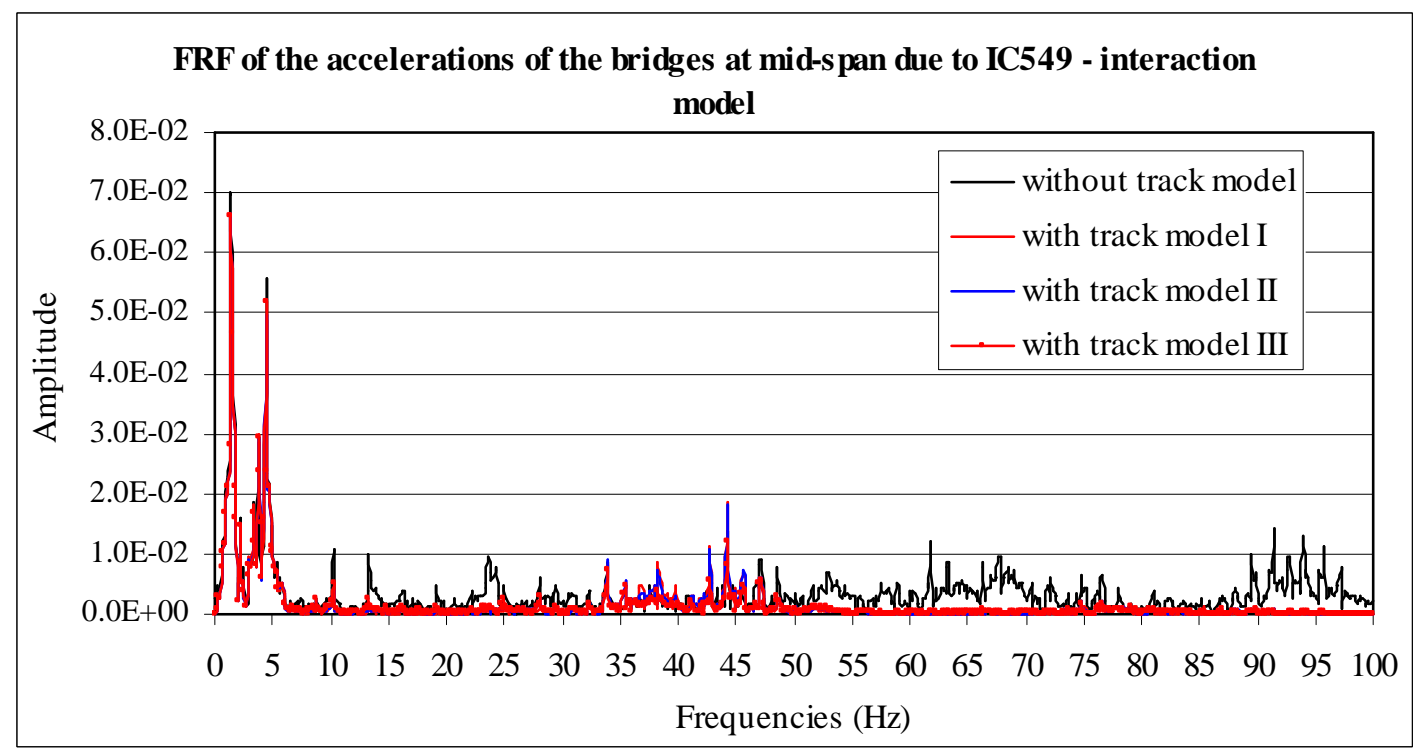

Figure 23: Comparison between the FRF of the accelerations of the bridge, with all the ballast track models for the ICE549 train under a speed of $140 \mathrm{~km} / \mathrm{h}$.

\section{CONCLUSIONS}

This study has the purpose of analyzing the behavior of one simply supported bridge under real traffic using bridge-track models. The experimental program reported in [15] concerning the identification of the dynamic characteristics of several bridges was the starting point for the numerical study presented here. The measurements of one of the bridges were used for comparison with the numerical results.

During the analysis it was confirmed that some non-linear effects at the supports together with the variation of the mass during the passage of the locomotives were responsible for the variation of the first frequency 
from about $3.7 \mathrm{~Hz}$ to $5.2 \mathrm{~Hz}$. When the bridge is under the effect of the traffic the first frequency remains between $3.7 \mathrm{~Hz}$ and $4.0 \mathrm{~Hz}$ and when the low amplitudes of vibration of the unloaded structure are used for system identification the first frequency increases more than $40 \%$.

Because the train velocities (130-140 km/h) used for the computations are much lower than the critical speed (about $380 \mathrm{~km} / \mathrm{h}$ ) the results obtained from the model of the bridge with and without any track model are very similar. Nevertheless, if the comparison is made in the frequency domain, we conclude that the ballast track Models I and II influence the response at a frequency range between 15 and $45 \mathrm{~Hz}$ and the track Model III seems to concentrate its influence around $20-25 \mathrm{~Hz}$.

According to the results obtained for the accelerations in the frequency domain, it can be concluded that the application of the Wilson $\theta$ method shows to be suitable in filtering the higher frequencies, instead of the Newmark method. The examples reveal a good numerical dissipation of the spurious participation of the higher modes when that method is used.

The consideration of the interaction model in the calculations shows that the exact knowledge about the data of the train, namely the mass, the stiffness and the damping of the first suspension, is very important for the accurate evaluation of the history response of the bridge. Future works will deal with this aspect and with the evaluation of the bridge response for train speeds in the range of the critical one.

\section{REFERENCES}

1. Fryba L. Vibrations of solids and structures under moving loads ( $3^{\text {rd }}$ edition) Thomas Telford, London 1999.

2. Knothe K, Grassie SL. Modeling of railway track and vehicle/track interaction at high frequencies. Vehicle System Dynamic 22, 209-262, 1993.

3. Popp K, Kruse H, Kaiser I. Vehicle-track dynamics in the mid-frequency range. Vehicle System Dynamic 31, 423-464, 1999.

4. Rebelo C, Heiden M, Pircher M, Simões da Silva L. Vibrations measurements on existing single-span concrete railway viaducts in Austria, EURODYN 2005, Paris, 2005, pp. 1637-1642.

5. Rigueiro C, Rebelo C. Simões da Silva L, Pircher M, Heiden M. Dynamic behavior of ballasted single railway bridges, Métodos Numéricos en Ingenieria 2005, Granada, 2005.

6. Rebelo C, Simões da Silva L, Pircher M, Rigueiro C, Heiden M. Vibrations measurements on small to medium single-span railway bridges, Experimental Vibration Analysis for Civil Engineering Structures - EVACES, Bordeaux, 2005.

7. Esveld C. Modern Railway Track, MRT Productions, Germany, 1989.

8. Zhai M, Wang Y, Lin H. Modelling and experiment of railway ballast vibrations, Journal of Sound and Vibration, 270, pp. 673-683, 2003.

9. Man A. A survey of dynamic railway track properties and their quality, $\mathrm{PhD}$. Thesis, TU Delft, DUP Science, Delft, 2002.

10. Yang Y B et al.. Vehicle-Bridge Interactions Dynamics: With applications to high speed railways, World Scientific, 2004.

11. ERRI D214. Rail Bridges for speeds $>200 \mathrm{~km} / \mathrm{h}$, Final Report, European Rail Research Institute, 1999.

12. ADINA, Automatic Dynamic Incremental Non Linear Analysis, ADINA R \& D, Inc. USA, 2003.

13. EN1991-2, Actions on structures - Part 2: General actions - Traffic loads on Bridges. European Committee for Standardization, CEN, 2003.

14. TDV GesmbH. RM2004 - Software \& Techincal Description, Graz, Austria, 2004.

15. EN1990-prAnnex A2, Basis of Structural Design - Annex A2: Application for bridges (normative), Final Draft. European Committee for Standardization, CEN, 2002.

16. Bathe K J. Finite Element Procedures, prentice-Hall, 1996. 